\title{
Os direitos humanos à comunicação e à informação: Reflexões a partir do Cárcere Brasiliense
}

\author{
Human rights to communication and information: \\ Reflections from the Jail Brasiliense
}

\section{Derechos humanos a la comunicación e información: Reflexiones desde la Cárcel Brasiliense}

\author{
Milena dos Santos Marra \\ Universidade Federal de Goiás, UFG, Brasil \\ http://lattes.cnpq.br/0547475863035302 \\ milena.bmarra@gmail.com
}

Fernando Oliveira Paulino

Universidade de Brasília, UnB, Brasil

https://orcid.org/0000-0002-4946-0513

http://lattes.cnpq.br/2907708501435465

paulino@unb.br

\begin{abstract}
Resumo: Este trabalho resulta de reflexões acerca dos direitos à comunicação e à informação como direitos humanos diante da situação de privação de liberdade. Apesar da abrangência do tema, este artigo trabalhou com as penitenciárias feminina e masculina do Distrito Federal. O objetivo foi perceber como os direitos à comunicação e à informação são percebidos pelos familiares dos presidiários(as) locais e, principalmente, se são considerados como direitos humanos. Entre outros, o embasamento teórico foi dado pela concepção de "O Direito Achado na Rua" (2017), de Souza Júnior et. al. Os resultados apontaram três entendimentos: uma invisibilidade social dos direitos humanos à comunicação e à informação; o de direitos humanos reservados aos humanos direitos; e uma visão maniqueísta do sistema carcerário e simplista acerca dos direitos à comunicação e à informação.
\end{abstract}

Palavras-chave: Direitos humanos. Direito à comunicação. Direito à informação. 


\begin{abstract}
This work results from reflections on the rights to communication and information as human rights in the face of deprivation of liberty. Despite the scope of the theme, this article worked with the female and male penitentiaries of the Federal District. The objective was to understand how the rights of communication and information are perceived by the families of the local inmates and, especially, if they are considered as human rights. Among others, the theoretical basis was given by the conception of "The Right Found in the Street" (2017), de Souza Júnior et. al. The results pointed out three understandings: a social invisibility of human rights to communication and information; the human rights reserved for human rights; and a manichean view of the prison system and simplistic about the rights to communication and information.
\end{abstract}

Key words: Human rights. Right to communication. Right to information.

Resumen: Este trabajo resulta de reflexiones acerca de los derechos a la comunicación ya la información como derechos humanos ante la situación de privación de libertad. A pesar del alcance del tema, este artículo trabajó con las cárceles femenina y masculina del Distrito Federal. El objetivo fue percibir cómo los derechos a la comunicación ya la información son percibidos por los familiares de los presidiarios locales y, principalmente, si son considerados como derechos humanos. Entre otros, el fundamento teórico fue dado por la concepción de "El Derecho Encontrado en la Calle" (2017), de Souza Júnior et. al. Los resultados apuntaron tres entendimientos: una invisibilidad social de los derechos humanos a la comunicación ya la información; de derechos humanos reservados a los derechos humanos; y una visión maniqueísta del sistema carcelario y simplista acerca de los derechos a la comunicación ya la información.

Palabras-clave: Derechos humanos. Derecho a la comunicación. Derecho a la información.

\title{
Introdução
}

Ainda há um longo caminho a ser percorrido para a efetivação dos direitos humanos no Brasil. As conquistas desses direitos foram permeadas por impasses e desafios que o país enfrentou, inclusive, tempos de retrocesso e supressão de garantias. Em um contexto como esse, a desigualdade incessante faz com que 
alguns indivíduos permaneçam historicamente à margem de direitos básicos.

Quando se fala sobre indivíduos marginalizados, questionar o tratamento dado aos direitos dos presidiários brasileiros apresenta-se como um desafio, sobretudo no que diz respeito à comunicação. Hoje em dia, a situação do preso continua sendo de exclusão e, apesar de não ser tão simples, diferenciar os direitos que não devem ser afetados por sanções penais e questionar a garantia dos que devem prevalecer assegurados torna-se indispensável. Nesse sentido, há uma necessidade permanente de se problematizar o direito humano à informação e à comunicação como influenciadores diretos na sobrevivência humana no âmbito dessas instituições.

Dessa forma, percebe-se a problemática de que trata este artigo: na cadeia, embora algumas restrições sejam inerentes à pena (privação de liberdade, restrição de contato presencial com outros indivíduos, controle de visitas), outras são discutíveis (acesso restrito aos jornais, exposição à TV e às notícias de interesse público). Em alguns casos, este deixa de ser visto como uma necessidade humana e passa ser entendido de forma desfavorável: como uma prerrogativa ou um benefício.

O presente artigo utilizará os dados da pesquisa CATATAUS E CHORONAS: a comunicação por meio de bilhetes e cartas nas penitenciárias do DF, de mesma autoria, realizada por meio de entrevistas presenciais e apresentada à Faculdade de Comunicação da Universidade de Brasília. Desse modo, a intenção desse artigo é apropriar-se dos resultados obtidos na pesquisa para ampliar a discussão sobre um novo assunto: o reconhecimento que as pessoas têm dos direitos à comunicação e à informação como direitos humanos, sobretudo quando estão expostas à situação de privação de liberdade. Além disso, refletir sobre as demandas, as objeções, as particularidades e fatores determinantes, além dos mais diversos aspectos dessa temática.

\section{A Comunicação e a Informação como direitos humanos}


A intenção de se discutir os direitos à comunicação e à informação em situação de cárcere propõe uma análise que compreende a comunicação como fundamental às transformações sociais em detrimento de uma visão maniqueísta em relação à prisão. É preciso entender que os direitos à comunicação e à informação surgem porque o ser humano desenvolve as formas mais complexas de interação e convivência.

Convivendo em sociedade, os indivíduos têm necessidade de comunicação. Como um ser social, o indivíduo precisa saber o que se passa ao seu redor, conhecer e ter informações. Essa necessidade vai desde poder se expressar até fazer-se ouvir e rompe com sua individualidade, contribuindo para o desenvolvimento pessoal e influenciando a sua vida. Falar em comunicação, então, significa falar de existência em um ambiente coletivo permeado por inúmeras relações humanas.

Além disso, a comunicação também é uma necessidade cognitiva. O indivíduo possui necessidades fundamentais como correspondência, contato e reconhecimento. Sem comunicação, nenhuma dessas atividades estará plenamente satisfeita. De certa forma, a comunicação representa um pressuposto para a convivência em sociedade, ou seja, "é questão de sobrevivência tanto individual - físico, emocional e psíquica - quanto social e política" (SILVA, 1997, p.54).

$\mathrm{O}$ direito à informação também pode ser percebido como um direito humano, isso porque se apresenta como um pré-requisito para que se possa falar em participação política e cidadã. Dada essa necessidade, ao longo do século XX, o direito à comunicação foi progressivamente incorporado aos marcos jurídicos como um direito a ser garantido a todas as pessoas.

Em 1948, a Declaração Universal dos Direito do Homem consolidou seu artigo 19 conhecido por afirmar que "todo indivíduo tem direito à liberdade de opinião e de expressão; este direito inclui a liberdade de, sem interferência, ter opiniões e de procurar, receber e transmitir informações e ideias por quaisquer meios, independentemente de fronteiras" (ASSEMBLEIA GERAL DAS NAÇÕES UNIDAS, 1948, art. 19). 
Diante do contexto socioeconômico e político da época, o direito à Comunicação tornou-se oficialmente apresentado com o Relatório MacBride em 1983. Oficialmente conhecido como "Um mundo e muitas vozes", o relatório discutiu o poder da comunicação restrito ao mercado e ao Estado, quando deveria ser concentrado nas mãos da sociedade civil. De acordo com o Relatório MacBride (1983), o direito à Comunicação equivale ao direito de todas as pessoas produzirem, distribuírem e acessarem informação e cultura em equânimes condições.

Entende-se que esses direitos estão diretamente ligados à garantia da democracia e, assim como outros dos direitos sociais, econômicos e culturais, representam um avanço para a busca de igualdade. Desse modo, o direito à comunicação surge como um objetivo principal de solucionar alguns problemas, promover a paz e, principalmente, o desenvolvimento humano por meio da comunicação.

Sem a garantia dos direitos humanos à comunicação e à informação, a sociedade como um todo é prejudicada. A garantia de tais direitos, além de dar voz aos que há muito não são ouvidos, proporciona também avanços em termos de condições enquanto seres humanos. Estes podem tanto emancipar a humanidade quanto a sua ausência perpetuar desigualdades que movem as violações à dignidade humana.

Sousa Junior et al (2017, p. 100) explicam que o direito à comunicação é um dos pilares centrais de uma sociedade justa e democrática. Assumir a comunicação como um direito humano significa reconhecer o direito de todos terem voz e "reconhecer a comunicação como um direito universal e indissociável de todos os outros direitos fundamentais" (idem). O direito à comunicação é um direito que deve ser garantido em todos os seus aspectos. Seja por meios legais, seja por regulamentos garantidores, a sociedade precisa ter clareza que este direito é tão importante quanto o acesso à escola, a saúde.

No Brasil, toda essa discussão em torno dos direito humanos à comunicação e à informação intensifica-se principalmente pela atuação dos movimentos sociais, pois enfatizam que o sujeito para exercer seus direitos deve possuir não só o acesso à informação ou à comunicação, mas também ser protagonista de seu conteúdo e meios (PERUZZO, 2004). Ou seja, "a 
concepção da comunicação como direito humano está inserida numa matriz de pensamento que compreende os direitos como instrumentos de luta políticohegemônica por uma sociedade justa, igualitária e sem opressão de qualquer tipo" (RODRIGUES, 2010, p.21).

Para considerá-los como um direito humano, portanto, é possível apontar o protagonismo do sujeito como uma carência a ser questionada no contexto dos direitos à informação e à comunicação. Esse entendimento relaciona-se com a perspectiva que os percebe como achados na rua. Isso significa que sob a perspectiva de $O$ Direito Achado na Rua, a comunicação e a informação apresentam-se não como direitos jurídicos resumidos à dimensão constitucional ou administrativa, mas direitos humanos resultantes da luta de movimentos sociais e dos sujeitos coletivos de direitos.

O Direito Achado na Rua é uma perspectiva que pensa o direito como a superação de privilégios, questiona a unidade e a centralidade de jurisdição nas mãos do Estado e propõe protagonismo à sociedade civil e ao pluralismo jurídico no Brasil. Rua é uma metáfora de espaço público disputado por diversas instâncias e atores sociais envolvidos. Em relação às penitenciárias, essa concepção propõe o debate coletivo sobre o que é conflituoso, ou seja,

O Estado não desconhece o problema, pois o próprio Levantamento Nacional de Informações Penitenciárias cita que é difícil compatibilizar a garantia de direitos com a natureza da pena da prisão. Isso se deve principalmente ao fato de que o número de pessoas presas cresce rapidamente e outras prioridades das políticas públicas impedem que recursos compatíveis com aqueles que seriam necessários para essa garantia sejam investidos (INFOPEN, 2014). A situação de prisão está historicamente associada às doenças como a Aids e a tuberculose, à violação do direito à integridade física, e mesmo à violação ao direito à vida, "de forma mais contundente do que ocorre com a população em geral” (MACHADO, 2016, p.2).

O presídio é uma instituição totalitária no que diz respeito à presença de mecanismos de poder presentes neste local. Lá estão um grande número de pessoas com situação semelhante que, privados de sua liberdade, organizam-se para viver sob o Poder disciplinar. A prisão desses indivíduos é uma forma de 
inseri-los em um regime disciplinar intenso, uma maneira de controlar sua existência e produzir obediência. "Apesar de muitos governos pretenderem dizer-nos o contrário, a prisão está, em primeiro lugar, essencialmente organizada para punir os excluídos, controlando-os de forma segura durante um período de tempo definido por tribunal" (CARLEN, 2007, p.1009).

Marco Cepik (2000, p.10) explica que a situação do Brasil está bem distante de ser ideal, pois "mesmo em relação à legislação existente em outros países, até a delimitação jurídica do direito à informação no Brasil é muito precária”. Isso não é um fato isolado, desde a Coroa já existem indícios de esquecimentos em relação à comunicação e à informação no Brasil. Paulo Freire (1967, p.66) esclarece que “o Brasil nasceu e cresceu sem experiências de diálogo. De cabeça baixa, com receio da Coroa. Sem imprensa. Sem relações. Sem escola. Doente. Sem fala autêntica".

A importância de se afirmar os direitos à comunicação e à informação como direitos humanos surge do que Gomes (1989, p.30) chama de diminuição da capacidade de ser gente, condição ocasionada por cerceamentos da comunicação e da liberdade de comunicação. "Isto é, a falta de comunicação torna-se opressão e dominação sobre as pessoas, limitando o direito de ser”.

Limitações desse tipo, para Hannah Arendt (2007), demonstram uma violação ao homem e sua condição, uma vez que restringe seus direitos e o resume apenas a própria existência. A autora talvez nos mostre a chave para a compreensão de experiências totalitárias, que privam a população, ao mencionar a perda da condição humana dos que não se adequam ao sistema: os humanos não direitos.

No início dos movimentos nazistas e stalinistas, existiam pessoas como os desempregados, refugiados, apátridos, homossexuais e marginais, que eram percebidos pelas outras pessoas como seres supérfluos, seres despidos de qualquer utilidade (ARENDT, 2007, p.524).

Também para Foucault (1975), as instituições totalitárias possuem rituais políticos. Inquestionáveis, quando aplicados aos detentos, são parte da mesma estrutura de perpetuação do poder vista do lado de fora das penitenciárias. Eles fazem parte "mesmo de um modo menor, das cerimônias 
pelas quais se manifesta o poder [na sociedade]" (idem, p.41). O poder do Estado tira dos presos a sua liberdade e determina do que serão privados. Este é soberano sobre as vidas e age coercitivamente em forma de castigos e restrições. Os sistemas de limitação e coerção são instrumentos utilizados de forma exclusiva pelo Estado para disciplinar e manter controle sobre a população carcerária (idem, p.15).

Em um contexto em que a ressocialização é o verdadeiro fim esperado, Leite (2004, p.46) explica que "a informação permite que o infrator possa acompanhar os desdobramentos do mundo exterior no lapso de tempo em que está privado de sua liberdade”. Dessa maneira, apesar de estar provisoriamente afastado, o acesso à comunicação e à informação contribuem para a função educadora da pena, "pois o condenado terá menor dificuldade em se adaptar a uma sociedade que não the é desconhecida, apesar do período de afastamento" (idem, p.51).

\section{A importância do reconhecimento dos Direitos à Comunicação e à Informação como direitos humanos: a experiência do cárcere brasilense.}

Os dois estabelecimentos que contemplaram a pesquisa sobre a qual este trabalho trata são: a Penitenciária do Distrito Federal I - PDF e a Penitenciária Feminina do Distrito Federal - PFDF. A primeira, conhecida como Papuda, é classificada como Unidade de Segurança Média, existe há 38 anos e, há 16, tornou-se o maior estabelecimento penal de regime fechado de todo o Distrito Federal. A segunda, conhecida por Colmeia, também de Segurança Média, é destinada ao recolhimento de mulheres sentenciadas ao cumprimento de pena privativa de liberdade em regime fechado e semiaberto.

Para tentar aproximar o objetivo da pesquisa com essa população, as entrevistas foram realizadas com pessoas que foram realizar visitas ao Pavilhão de Entorpecentes da Papuda e Colmeia - locais responsáveis por abrigar os internos(as) que cometeram o crime de tráfico de drogas. Para amostragem, foram entrevistadas 10 pessoas/visitantes do presídio masculino e 10 pessoas/visitantes do presídio feminino.

No roteiro da pesquisa, optou-se por não contemplar questões relativas 
às demais infrações penais que o interno ou a interna pudessem ter cometido, embora essa narrativa tenha voluntariamente surgido em muitas respostas da entrevista. Essa escolha se justifica no sentido em que, para este trabalho, não interessa expor e detalhar a trajetória criminal da população carcerária brasiliense, mas questionar direitos de pessoas que, independentemente de ter ou não cometido uma infração, são cidadãos. "Seria preciso ver os internos e condenados, primeiramente, como seres humanos e, portanto, como portadores de direitos, reconhecendo o fenômeno da cidadania onde ele tem sido tradicional e solenemente negado" (ROLIM, 2004, p.6).

Dentre as perguntas da pesquisa original, a que norteia as reflexões deste trabalho é a Qual o reflexo dessa comunicação na sua vida e na de seu familiar? No âmbito da pesquisa anterior, referia-se ao envio de cartas às penitenciárias, mas as respostas trouxeram novas reflexões para este trabalho. Abaixo, a imagem apresenta visualmente, e de forma hierarquizada, as principais palavras encontradas nas respostas recebidas para a pergunta apresentada anteriormente.

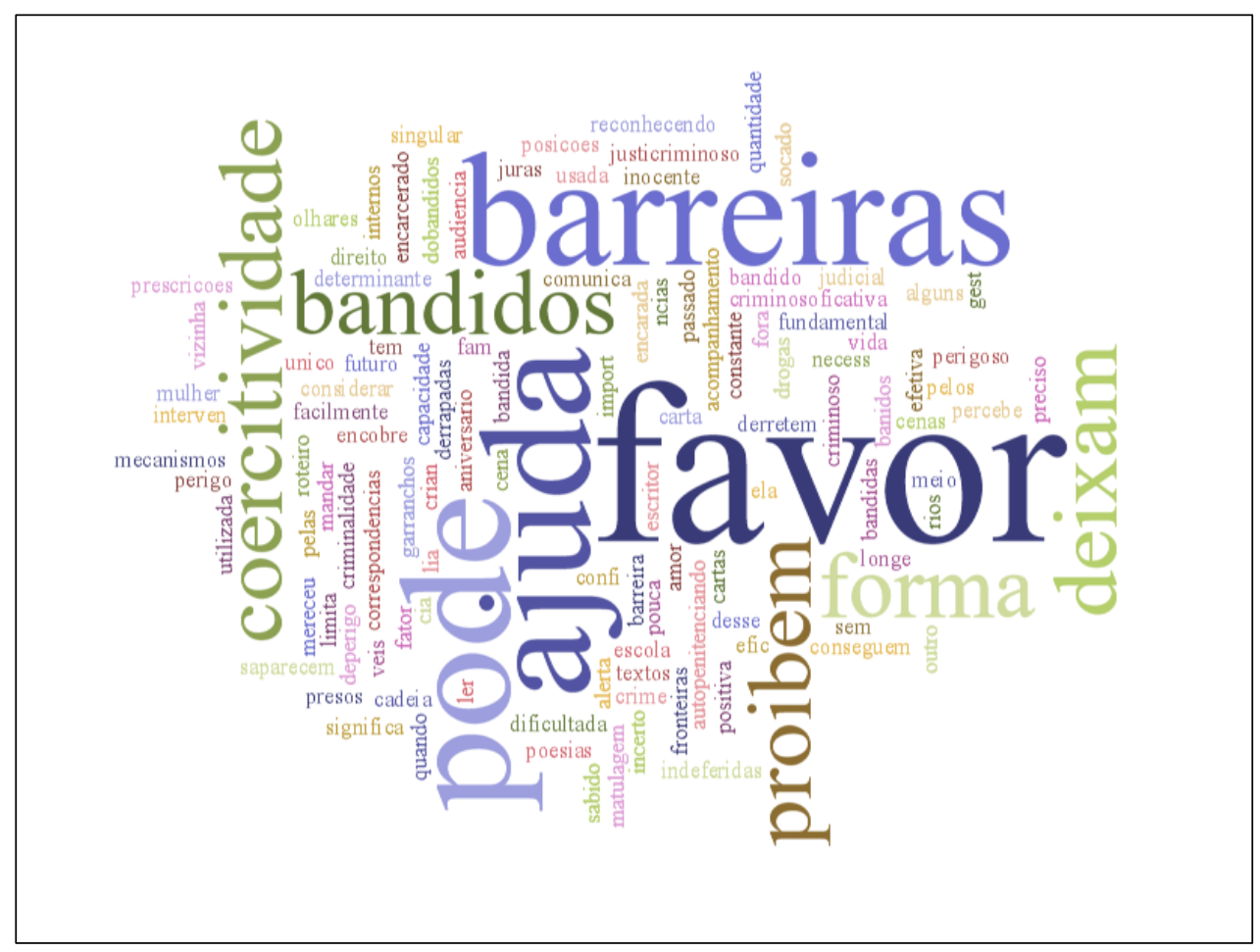


Diante dos resultados percebidos, três fatores reiteradamente usados como respostas foram identificados:

- $\quad \mathrm{A}$ invisibilidade social dos direitos humanos à comunicação e à informação;

- Os direitos humanos reservados aos humanos direitos;

- A visão maniqueísta do sistema carcerário e simplista acerca dos direitos à comunicação e à informação;

A invisibilidade social dos direitos à comunicação e à informação diz respeito à dificuldade que as pessoas entrevistadas possuem para compreendêlos como direitos humanos. De acordo com as respostas apresentadas, é possível perceber que as pessoas entrevistadas não entendem os direitos dos quais este trabalho trata como uma condição necessária à pessoa presa. Sousa Junior et al. (2016) explicam que os direitos humanos à comunicação e à informação não são vistos da mesma forma que o à saúde, à educação, à segurança, à habitação, pois estes "já que suas carências são facilmente identificáveis". Já os direitos humanos à comunicação e à informação nem sempre conseguem a mesma materialidade. "Ambos sofrem de certa invisibilidade social. Lutar com quem, para quê e por quê?” (idem, p. 25).

Nas entrevistas, há relatos significativos para o entendimento da importância social do desses direitos dentro das penitenciárias brasilienses. "Meu marido tem outra filha no Maranhão. Quando ele foi preso, sentiu que deveria falar mais com a menina [a filha] que ele não via desde que era uma bebê. Então no início ele ia pedindo para um colega aqui, outro ali, escrever umas coisas que vinham na cabeça. Hoje, ele mesmo faz [cartas] com os garranchos dele sozinho e a menina já sabe decifrar" diz uma entrevistada sobre seu marido que, segundo ela, é semianalfabeto.

Essa dificuldade de reconhecimento dos direitos à comunicação e à informação como direitos humanos apresenta-se como um dos empecilhos para a sua efetivação. Entende-se que o reconhecimento da violação de um direito é fator determinante para que se questione sua garantia. Para Gallardo (2014), os 
direitos humanos não são garantidos nos âmbitos dos códigos ou das leis, mas nas lutas. Sousa Junior et al (2016, p.92) apontam a força do reconhecimento solidário de homens e mulheres diante da violação de seus direitos, "na medida de sua organização, podem ser identificados como movimentos sociais orientados para a transformação das suas condições materiais e das estruturas de poder no âmbito da sociedade".

Em relação às respostas que podem ser caracterizadas como os Direitos Humanos são reservados aos humanos direitos, não é uma problemática reservada à comunicação, mas de todo o campo dos direitos humanos. "E é difícil pensar em Direitos Humanos quando tantos os tratam como um privilégio restrito a humanos direitos" (idem, 2016, p.20). Esse entendimento filantrópico dos direitos humanos à comunicação e à informação confronta a visão de universalização proposta pela Declaração dos Direitos Humanos, pressuposto fundamental à emancipação dos oprimidos e dos explorados.

No Brasil, ainda há preconceitos e estereótipos de pessoas mais humanas ou mais cidadãs em detrimento de outras. Tal contraste pode gerar um desequilíbrio informacional, pois "as sociedades em que se nega o diálogo - a comunicação - e, em seu lugar se lhes oferecem comunicados resultantes de compulsão ou doação, se fazem preponderantemente mudas" (DUARTE, 2007, p.95). Nessa segunda categoria, critérios comuns entre a população carcerária são justificativas apresentadas para julgá-la como não pertencente aos cidadãos.

Ainda que se considere todas as dificuldades existentes aos profissionais dos presídios, a limitação dos direitos à comunicação e à informação a parcelas da população carcerária confrontam os valores da universalidade. Há relatos como "— Eu evito questionar para não gerar problemas para minha filha" que explicam que familiares livres e não sentenciados, de certa forma, são parte das pessoas prejudicadas pela fragilidade das garantias do direito à comunicação e à informação.

Sousa Junior et al (2017, p.20) explicam que falar de Direitos Humanos é apontar limites, mas também possibilidades. "O primeiro limite é sua aspiração à universalidade, num mundo marcado pelas diferenças, tensões e conflitos, ocultando seu DNA ocidental, europeu e branco". Relacionado a esse 
ocultamento, está uma percepção, sobretudo entre as classes sociais menos favorecidas e mais vulneráveis, “de que eles são ineficazes e inócuos diante da demanda por respostas rápidas e diretas para a violência e para a falta de acesso e de oportunidades" (2016, p.20).

Por último, a visão maniqueísta do sistema carcerário e simplista acerca dos direitos à comunicação e à informação traz uma série de respostas recebidas que demonstram que, por um lado, estes enxergam o sistema carcerário de forma maniqueísta e, por outro, também o percebem de forma simplista e resumida.

A visão maniqueísta do sistema carcerário tende a separar os aprisionados de um lado e a instituição de outro em conceitos opostos e incompatíveis. Por um lado, a instituição é apontada de forma negativa e arbitrária e, por outro, como defensora da justiça e do bem-estar social. Da mesma forma, ora os visitantes apontam a população carcerária como vítima, ora apontam-nos como criminosos de alta periculosidade.

Relatos como "- É muito bom que eles [o presídio] nos deixem enviar correspondências. Tenho medo que um dia eles [novamente o presídio] não nos ajudem mais" trazem a reflexão de que esses direitos são percebidos de forma assistencialista, filantrópica: como um favor que a Penitenciária dá aos presos.

Em relação à comunicação, essa visão maniqueísta prejudica o entendimento acerca das responsabilidades sobre a garantia dos direitos humanos à comunicação e à informação, uma vez que não há a pretensão de definir quem realiza as transgressões, mas de cessá-las.

A visão simplista acerca dos direitos à comunicação e à informação está intrinsecamente relacionada a outros direitos e às condições nas quais a população carcerária e seus familiares estão inseridos. $\mathrm{O}$ direito à comunicação deve ser associado aos outros direitos essenciais da pessoa presa, sobretudo em uma conjuntura em que ele ainda é entendido como uma regalia.

Além disso, Diniz (2015, p. 211) relembra que a responsabilidade da garantia de direitos não deve ser apontada aos funcionários dos presídios, pois “os trabalhadores são agentes da máquina do abandono. Não é contra eles que o dedo do julgamento deve ser posicionado". Para que os direitos humanos à comunicação e à informação alcancem as pessoas em situação de privação de liberdade atualmente, 
as políticas públicas devem não só ser incorporadas no ordenamento jurídico, mas adequadas às singularidades da realidade prisional existente no país.

Por último, em relação ao exercício desses direitos, percebe-se que a ilegalidade é frequente. No trabalho que deu origem a este, as entrevistadas afirmaram com clareza " “ Nós utilizamos meios ilegais para receber ligações e correspondências" e afirmam " - Se vou visitar meu marido na cadeia e ele me dá uma carta, por exemplo, eu vou sair com ela. Não há nada de errado escrito ali, é um presente" e "Sim, já saí muitas vezes com cartas falando coisas boas. Isso é proibido nas unidades prisionais porque não sabem o que está escrito nelas. Os agentes penitenciários não veem, eu as escondo embaixo da roupa”. Uma diz “Eu não posso trazer meus filhos pra cá [cadeia], então o pai deles [o preso] me dá cartas para eu levar para eles" e outra diz que "— Sim, muitas vezes saímos com as cartas nas calças e, quando tem revista na saída, eles [a Segurança] tomam e deixam o interno de castigo".

Cabe aqui a reflexão sobre até que ponto todos os problemas e dificuldades apresentadas anteriormente interferem de forma negativa na utilização desses meios, sem deixar de considerar ilegalidades de ambos os lados - administração e internos. É preciso repensar se essas ilegalidades seriam menores caso os direitos à comunicação e à informação fossem plenamente garantidos. De fato, o ato ilegal não se justifica, mas demonstra a fragilidade da comunicação dentro dos presídios brasilienses.

\section{Considerações Finais}

Embora este trabalho não tenha buscado compreender a complexidade em que as vidas da população carcerária e de seus visitantes estão envolvidas, é possível perceber alguns desafios relacionados à privação de liberdade no Distrito Federal. Nesse sentido, levando em consideração que a pesquisa evidencia a fragilidade da comunicação nas penitenciárias do DF, nota-se que há a necessidade de se pensar os direitos humanos à comunicação e à informação considerando sempre o caráter excludente das pessoas presas e de seus familiares.

A falta de reconhecimento e de garantia dos direitos humanos à 
comunicação e à informação não se resume à população carcerária e aos seus familiares, apresentando-se como um problema coletivo. Desse modo, o Estado, a Instituição, os presidiários(as), os familiares, a sociedade civil devem, juntos, reservar atenção ao tema. Diante do contexto brasileiro, os esforços minimamente comprometidos com a ressocialização e o processo de humanização do preso(a) representam ganhos significativos ao país.

Por fim, futuras pesquisas são imprescindíveis. É papel da comunicação a identificação das particularidades, falhas e ameaças dessas demandas. Tornase necessário que as pesquisas atravessem os muros da cadeia e, lá dentro, aprimorem o diagnóstico do exercício desses direitos humanos.

A ausência de garantia de aplicação de direitos humanos à comunicação e à informação silencia as pessoas presas e representa a perpetuação de mais uma das formas de violação do sistema prisional brasileiro. Deixar de reconhecê-los também é deixar de reconhecer suas existências.

\section{Referências bibliográficas:}

ARENDT. Hannah. A Condição Humana. $10^{\mathrm{a}}$ ed. Rio de Janeiro: Forense Universitária, 2009.

BRASIL, Ministério da Justiça. Departamento Penitenciário Nacional. Levantamento Nacional de Informações Penitenciárias INFOPEN: 2014 - 2016. P. 4-80. Disponível em http://www.justica.gov.br/seus-direitos/politicapenal/documentos/infopen dez14.pdf. https://doi.org/10.1086/ahr/73.3.947.

CARLEN, Pat. A reclusão de mulheres e a indústria de reintegração. Anál Soc. 2007; 42(185): 1005-19.

CEPIK, Marco. Direito à Informação: situação legal e desafios da Informática Pública. Volume 02, Issue 02, p.43-56, (2000) disponível em: www.tinyurl.com/j8tl6tj.

DINIZ, Débora. Cadeia: relatos sobre mulheres, 1a edição, Rio de Janeiro, 2015.

DUARTE, Marcia Yukiko Matsuuchi. Comunicação e cidadania, in DUARTE, Jorge (org.). Comunicação pública: Estado, governo, mercado, sociedade $e$ interesse público. São Paulo: Atlas, 2007.

FREIRE, Paulo. Ação cultural para a liberdade. 9a Ed. São Paulo: Paz e Terra, 2001.

FOUCAULT, Michel. Vigiar e punir: nascimento da prisão; tradução de Raquel Ramalhete. - 38. ed. - Petrópolis, RJ: Vozes, 1975. 
GALLARDO, Helio. Teoria crítica: matrizes e possibilidades de direitos humanos(1a. ed.). (P. Fernandes, Trad.). São Paulo, SP: Unesp, 2014.

GOMES, Pedro Gilberto. O direito de ser: a ética da comunicação na América Latina. São Paulo: Paulinas, 1989.

GUARESCHI, Pedrinho A. O Direito Humano à Comunicação: pela democratização da mídia. Petrópolis, RJ: 2013

KOVACH, Bill e ROSENSTIEL, Tom. Os elementos do jornalismo / Bill Kovach e; tradução de Wladir Dupont. - São Paulo: Geração Editorial, 2003.

LEITE, Janaína Artero de Carvalho. $O$ acesso à informação e a restrição imposta nas instituições penitenciárias. Trabalho de Conclusão de Curso (graduação em Direito) - Faculdades integradas Antônio Eufrásio de Toledo, Presidente Prudente/SP, 2004.

MACHADO, Cristiano. Violação do direito à saúde do preso: a prevalência da tuberculose no sistema prisional. Jusbrasil, Brasília, v. 5, n. 1, p.2-8, 17 nov. 2016.

RODRIGUES, Diogo Moyses. O direito humano à comunicação: igualdade e liberdade no espaço público mediado por tecnologias. 2010. 30 f. Dissertação (Mestrado) - Curso de Comunicação Social, Faculdade de Direito, Universidade de São Paulo, São Paulo, 2010. https://doi.org/10.11606/d.2.2010.tde-15062011-151640.

PERUZZO, Cicilia Maria Khroling . Comunicação nos movimentos populares: a participação na construção da cidadania. 3 ed. São Paulo: Vozes, 2004. 342

ROLIM, Marcos. Prisão e ideologia: limites e possibilidades para a reforma prisional no Brasil. Site do Curso de Direito da UFSM. Santa Maria - RS. Disponível em: . Acesso em: 11. Ago 2006.

SILVA, Aluizio Ferreira da. Direito à informação, direito à comunicação: direitos fundamentais na constituição brasileira. São Paulo, 1997. 296 f. Tese (Doutorado em Direito Constitucional) - Pontifícia Universidade Católica de São Paulo, São Paulo, 1997. https://doi.org/10.11606/issn.2318-8235.v88i0p421-437

SOUSA JUNIOR, José Geraldo de et al (Org.). O Direito achado na rua: Introdução crítica ao Direito à Comunicação e à Informação. Brasília: Fac Livros, 2017. 8 v. Disponível em:

https://faclivros.files.wordpress.com/2017/03/faclivros_direitoachadorua8.pdf.

Acesso em: 19 nov. 2017.

UNESCO. Um mundo e muitas vozes: Comunicação e informação na nossa época. Rio de Janeiro: FGV, 1983.

Data Recebimento: 07/05/19

Data Aprovação: 01/07/19 